\title{
Experimental Investigation of Performance of a Miniature Direct Methanol Fuel Cell in Short-Term Microgravity
}

\author{
Fang Ye • Feng Wu $\cdot$ Jian Fu Zhao • Hang Guo • \\ Shi Xin Wan · Cui Ping Lv • Chong Fang Ma
}

Received: 1 December 2009 / Accepted: 22 July 2010 / Published online: 12 August 2010

(C) Springer Science+Business Media B.V. 2010

\begin{abstract}
Experimental study of a liquid fed direct methanol fuel cell has been conducted in different gravity environments. A small single cell with $5 \mathrm{~cm} \times$ $5 \mathrm{~cm}$ active area has single serpentine channel on the graphite cathode polar plate and 11 parallel straight channels on the graphite anode flow bed. Cell voltage and current have been measured and two-phase flow in anode channels has been in situ visually observed. The experimental results indicate that the effect of gravity on power performance of the direct methanol fuel cell is large when the concentration polarization governs fuel cells operation. Gravitational effect becomes larger at higher current density. Increasing methanol feeding molarity is conducive to weaken the influence of gravity on performance of liquid fed direct methanol fuel cells. Increasing feeding flow rate of methanol solution from 6 to $15 \mathrm{ml} / \mathrm{min}$ could reduce the size of carbon
\end{abstract}

F. Ye $(\varangle) \cdot$ F. Wu · H. Guo · C. P. Lv · C. F. Ma

Key Laboratory of Enhanced Heat Transfer

and Energy Conservation, Ministry of Education,

College of Environmental and Energy Engineering,

Beijing University of Technology, 100 Ping Le Yuan,

Chaoyang District, Beijing, 100124,

People's Republic of China

e-mail: yefang@bjut.edu.cn

F. Ye $\cdot$ F. Wu $\cdot$ H. Guo $\cdot$ C. P. Lv C. F. Ma

Key Laboratory of Heat Transfer and Energy Conversion, Beijing Municipality, Beijing University of Technology,

Beijing, 100124, People's Republic of China

\section{J. F. Zhao · S. X. Wan}

Institute of Mechanics, Chinese Academy of Sciences,

Beijing, 100190, People's Republic of China dioxide bubbles, while the influence of gravity still exist. Transport phenomena inside direct methanol fuel cells in microgravity is also analyzed and discussed.

Keywords Direct methanol fuel cells • Microgravity • Two-phase flow

\section{Introduction}

Requirements of compact system design, easy refueling, low cost of fuel, quick start-up, ambient temperature and pressure operation have made direct methanol fuel cells (DMFC) an attractive power source for small unaided devices in spacecrafts.

In direct methanol fuel cells, methanol is directly oxidized on the anode side without any reforming process, while oxygen is introduced into the cathode and is reduced. The electrochemical reactions on anode and cathode of DMFC are as follows:

Anode: $\mathrm{CH}_{3} \mathrm{OH}+\mathrm{H}_{2} \mathrm{O} \rightarrow \mathrm{CO}_{2}+6 \mathrm{H}^{+}+6 \mathrm{e}^{-}$

Cathode: $\frac{3}{2} \mathrm{O}_{2}+6 \mathrm{H}^{+}+6 \mathrm{e}^{-} \rightarrow 3 \mathrm{H}_{2} \mathrm{O}$

Many researchers performed experiments of cell performance (Scott et al. 1999, 2001; Yang et al. 2007; Zhang et al. 2007) and fluid flow (Scott et al. 2001; Argyropoulos et al. 1999a, b; Guo et al. 2003, 2006; Nordlund et al. 2004; Lu and Wang 2004; Yang et al. $2005 a, b)$ in DMFCs in normal gravity condition. However, only few papers reported experimental study of fuel cells in microgravity. Guo et al. (2009a) experimentally investigated proton exchange membrane fuel cells (PEMFC) performance under different gravity 
conditions. A serpentine flow field was adopted on the cathode side. They found that in normal gravity, the liquid water accumulates in the bottom of the vertical flow channels of cathode flow bed and can not discharge effectively; but in microgravity, gas pushes the accumulated liquid water from the bottom of the channels to the outlet of cathode flow bed. They also investigated PEMFC performance and found that the performance of proton exchange membrane fuel cells is enhanced in microgravity because the transport resistance of oxygen is reduced by removing accumulated liquid water in flow channels. Guo et al. (2008a) reported their experiments of direct methanol fuel cells with gold plated stainless steel bipolar plates and preliminary analysis of the effect of gravity on mass transfer in DMFC. Their experimental results indicated that carbon dioxide bubbles stagnation in channels results in a negative influence on the mass transfer and performance of direct methanol fuel cells in microgravity when the DMFC operates at high current density. Guo et al. (2008b) visually observed liquid-gas two-phase flow in a DMFC anode channels of graphite bipolar plate in microgravity using drop tower. It was found that the size of bubbles in microgravity condition is larger than that in normal gravity. The flow pattern in anode channels could change bubbly flow in normal gravity to slug flow in microgravity. Guo et al. (2009b) experimentally studied the influence of the orientation of DMFC both in microgravity and normal gravity. The results indicated that in reduced gravity, the carbon dioxide bubbles rising speed in vertical channels is evidently slower than that in normal gravity. However, when the fuel cell orientation is horizontal, the slug flow is observed in microgravity and has almost the same behaviour with that in normal gravity (Guo et al. 2009b). From the open literature we can see that though a few papers investigate liquid-gas twophase flow in DMFC, the gravitational effect on power output performance of direct methanol fuel cells is still lacking.

In this paper, the influence of gravity on power output performance of a liquid fed DMFC was investigated experimentally. Transport phenomena inside direct methanol fuel cells in microgravity was also analyzed and discussed.

\section{Experimental}

The experimental system involves a direct methanol fuel cell, a oxygen tank, a oxygen flow rate controller (Cole Parmer, CZ-32907-67), a liquid flow rate me- ter (Cole Parmer, CZ-32908-43), a peristaltic pump (BT01), a high-speed video camera (VITcam CTC), a data acquisition unit (AQU1216) and other auxiliary devices (Fig. 1). Detailed information of experimental system is found in (Guo et al. 2009b). The flow rate controller can control the flow rate of oxygen from 0 to 1,000 standard cubic centimeter per minute (SCCM) with an error of $1 \%$ of full scale. The liquid flow rate meter can precise control the liquid flow rate form 0 to $50.0 \mathrm{ml} / \mathrm{min}$ with an error of $2 \%$ of full scale. The accuracy of the eight channel data acquisition unit is $0.1 \%$, the frequency of measurement is $1,000 \mathrm{~Hz}$.

A miniature direct methanol fuel cell consists of a membrane electrode assembly (MEA), two graphite bipolar plates, a transparent anode end plate, a stainless steel cathode end plate and sealing gaskets. The MEA comprises two carbon cloth gas diffusion layers (GDL), a Nafion 117 membrane with an active area of $50 \mathrm{~mm} \times$ $50 \mathrm{~mm}$ and the catalyst loading of $40 \mu \mathrm{g} / \mathrm{mm}^{2} \mathrm{Pt} / \mathrm{Ru}$ on the anode side and $40 \mu \mathrm{g} / \mathrm{mm}^{2} \mathrm{Pt}$ on the cathode side. The anode bipolar plate consist of 11 parallel straight channels with $2.0 \mathrm{~mm}$ (depth) $\times 2.5 \mathrm{~mm}$ (width) rectangle cross section and two header pipes. The length of single channel was $48.0 \mathrm{~mm}$. A single serpentine channel with $2.0 \mathrm{~mm}($ depth $) \times 2.5 \mathrm{~mm}$ (width) rectangular cross section was formed on cathode bipolar plate. The channel length was $566 \mathrm{~mm}$. Rib width on both

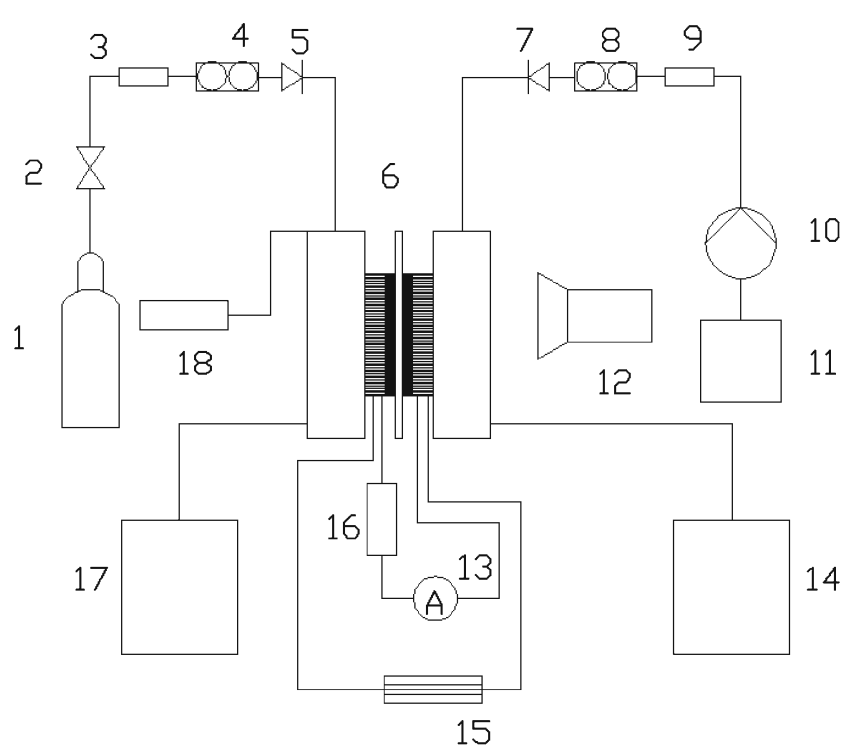

Fig. 1 Experimental system. 1 oxygen tank, 2 regulator, 3 and 9 filters, 4 flow rate controller, 5 and 7 one-way valves, 6 DMFC, 8 flow rate meter, 10 peristaltic pump, 11 liquid storage bag, 12 high speed video camera, 13 current transmitter, 14 liquid collector, 15 data acquisition unit, 16 electric resistors, 17 exhaust collector, 18 temperature control and heating unit 
anode and cathode was $2.0 \mathrm{~mm}$. The graphite bipolar plates was also used as current connector at the same time.

In the present experiments, all channels on the anode side were vertical, and the anode feeding header pipe was in the bottom of flow bed, and the discharge header pipe was on the top for $\mathrm{CO}_{2}$ bubbles removal. Oxygen gas with purity of $99.999 \%$ was fed as oxidant reactant without humidification and kept constant of $400 \mathrm{ml} / \mathrm{min}$.

In each microgravity experiment, the capsule, in which the experimental set-up was fixed, was released from upper storey of a drop tower after the fuel cell ran at $80^{\circ} \mathrm{C}$ for $70 \mathrm{~min}$. Capsule free falling in the drop tower of the National Microgravity Laboratory of Chinese Academy of Sciences could create $3.6 \mathrm{~s}$ effective microgravity environment, which residual gravity acceleration was $<10^{-2} \mathrm{~g}_{0}\left(\mathrm{~g}_{0}\right.$, ground gravity acceleration, $\left.9.81 \mathrm{~m} / \mathrm{s}^{2}\right)$.

\section{Results and Discussion}

Three electric loads, which had different value of resistance, are connected into the external circuit of DMFC, respectively. For every circuit load, experiments of the electric output performance of DMFC in normal gravity and microgravity were carried out, respectively. Difference of cell voltage vs. current density characteristics between normal gravity condition and micro gravity condition was obvious. The difference is larger at higher current density (Fig. 2). From data

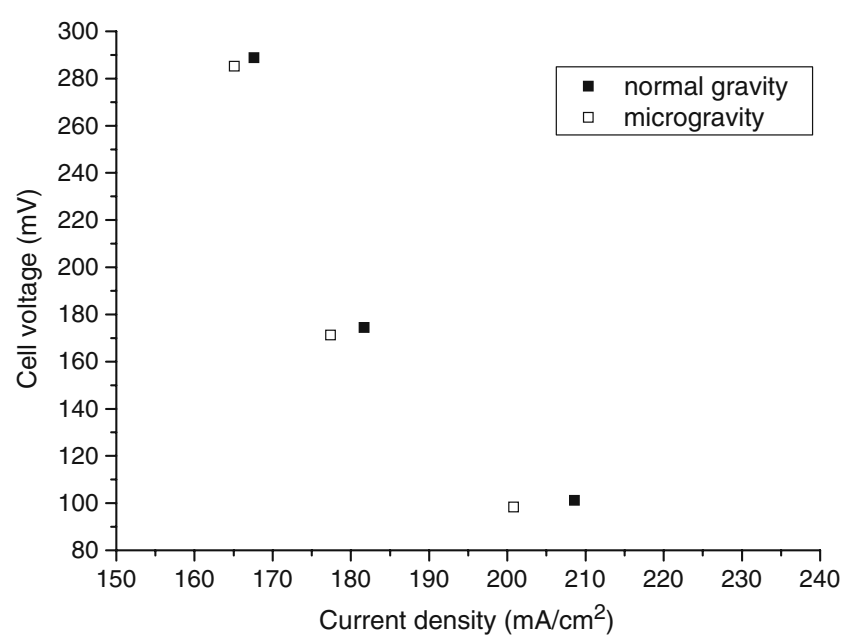

Fig. 2 Gravitational effect on performance of DMFC in Fig. 2 in concentration polarization region of the direct methanol fuel cell, it is known that mass transfer governs electric power generation of DMFC. Without the buoyancy lift force, the penetration in gas diffusion layer and flow in channels of $\mathrm{CO}_{2}$ are slower and the discharge of $\mathrm{CO}_{2}$, which is a product of anode electrochemical reaction, becomes more difficult in microgravity. Therefore, the accumulation of $\mathrm{CO}_{2}$ bubbles in channels is more serious at higher current density in microgravity environment. Large amounts of $\mathrm{CO}_{2}$ reduce the free area, which is necessary to the flow and penetration of methanol solution from channels to the catalyst layer. This weakens the anode electrochemical reaction and cause concentration polarization at the anode, which reduces the cell performance (Argyropoulos et al. 1999b). That is why the performance degradation in microgravity is larger at higher current density (Fig. 2). From Fig. 2 we inferred that the influence of gravity on mass transfer inside fuel cells results in the degradation of performance-in microgravity. From another point of view, if the mass transfer could be enhanced, the performance difference between normal gravity and microgravity condition will be smaller. This was confirmed by another experimental results shown in Fig. 3. The difference of cell performance in different gravities was relatively larger when the methanol feeding molarity was $500 \mathrm{~mol} / \mathrm{m}^{3}$, It implied that the mass transfer is still dominant. However, when the anode feeding concentration of aqueous methanol solution, which is reactant of anode electrochemical reaction (see Eq. 1), is increased to $1,500 \mathrm{~mol} / \mathrm{m}^{3}$, the cell performance in microgravity was almost the same with that in normal gravity.

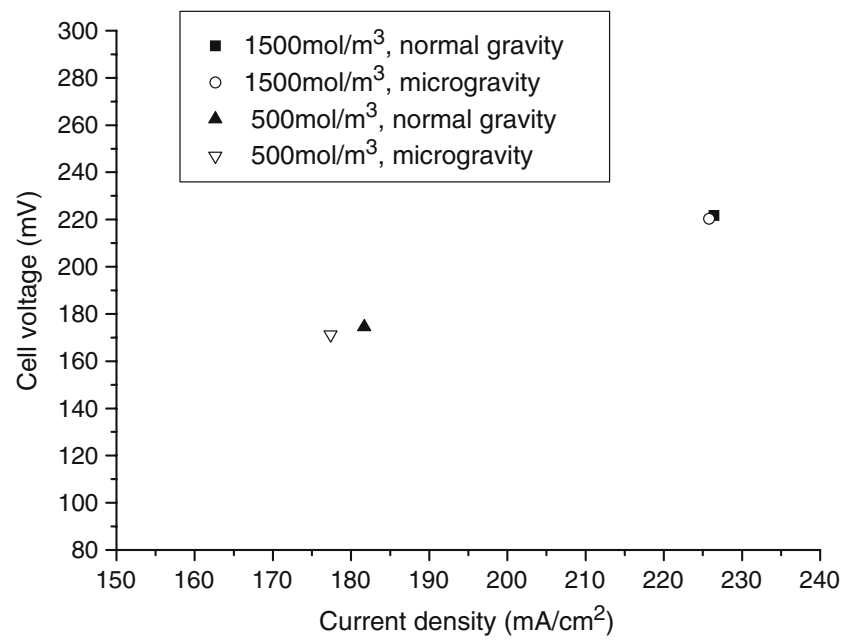

Fig. 3 Influence of methanol feeding molarity 


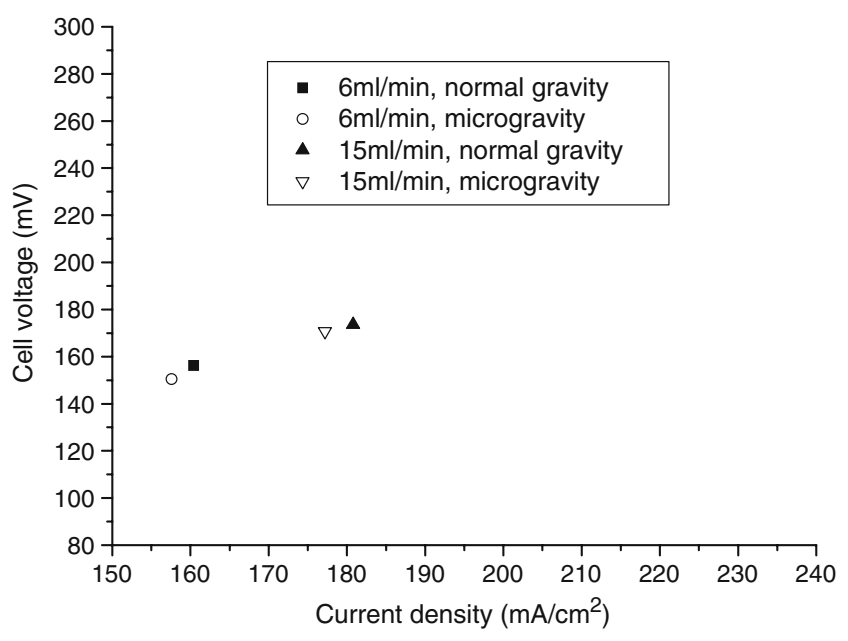

Fig. 4 Influence of feeding flow rate of methanol solution

Performance difference in microgravity and normal gravity was also occurred in varied flow rate of methanol solution in inlet header pipe (Fig. 4). However, the influence of flow rate on the performance difference was slight. The in situ visualization of twophase flow inside anode flow bed contributed to understand the reason. The images in Fig. 5 were taken at $1.6 \mathrm{~s}$ before releasing capsule, 1.6 and $3.2 \mathrm{~s}$ after free falling of capsule, respectively. Whether the feeding flow rate of methanol solution was 6 or $15 \mathrm{ml} / \mathrm{min}$, the evolution of carbon dioxide bubbles was similar. Bubbles became larger and larger in microgravity and finally, large bubbles or even slug occupied channels and blocked mass transfer of methanol solution from channels to anode catalyst layer and the most free area of gas diffuser layer. This blocking can impede the flow of fresh methanol solution, which is a reactant of anode electrochemical reaction, to the anode catalyst (Argyropoulos et al. 1999b), and the remain reactant of the dilute solution in catalyst layer cannot support the anode electrochemical reaction well. The gravitational effect on performance of DMFC is considerable when the concentration polarization is dominant in fuel cells operation.

Figure 5a also showed that small bubbles flowed from gas diffusion layer into anode channels and

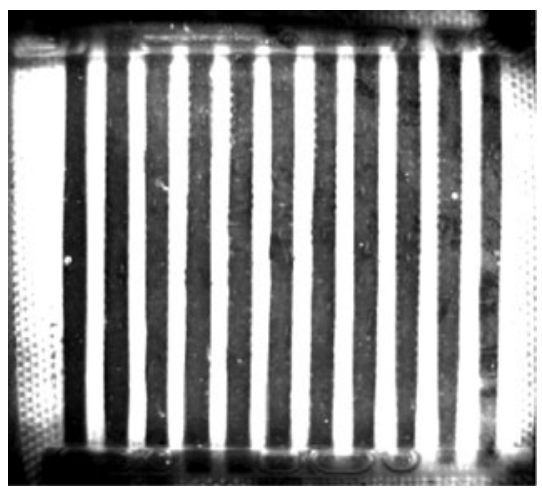

$-1600 \mathrm{~ms}$

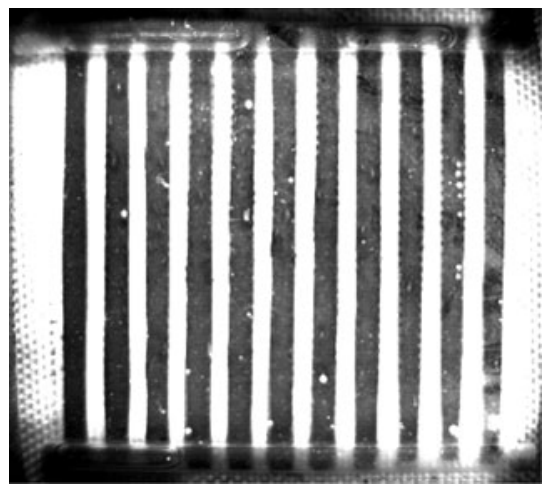

$-1600 \mathrm{~ms}$

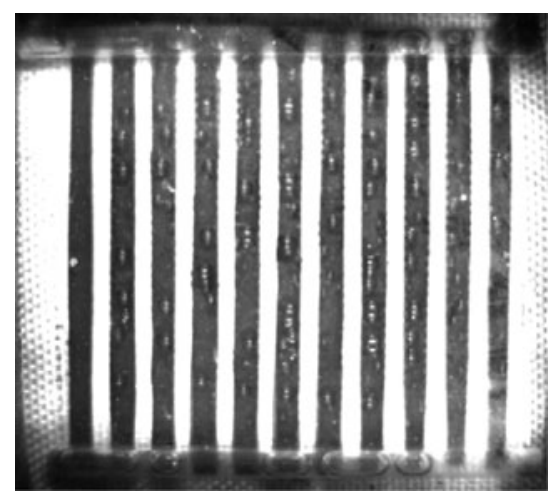

$1600 \mathrm{~ms}$

(a)

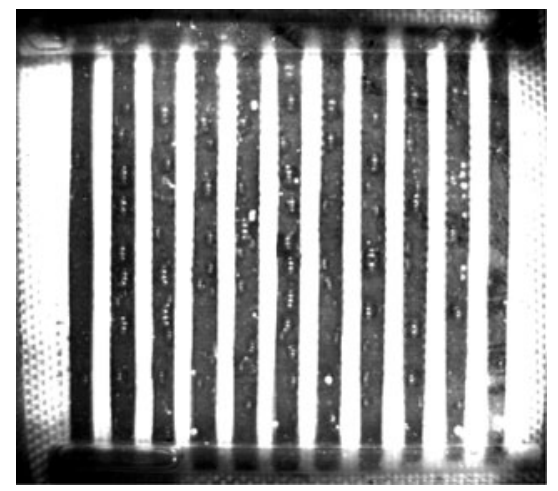

$1600 \mathrm{~ms}$

(b)

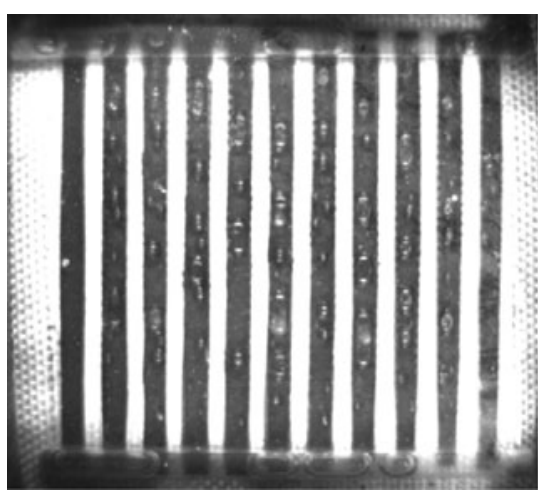

3200ms

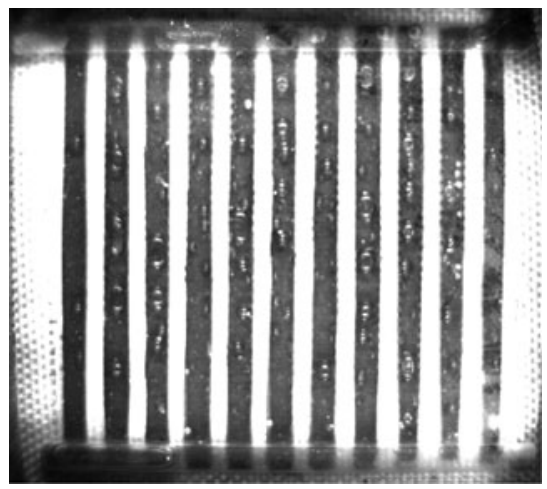

$3200 \mathrm{~ms}$

Fig. 5 Two-phase flow evolution in anode flow bed in normal gravity and microgravity. a Methanol solution feeding flow rate of $6 \mathrm{ml} / \mathrm{min}$. b Methanol solution feeding flow rate of $15 \mathrm{ml} / \mathrm{min}$ 
Table 1 Average velocity of $\mathrm{CO}_{2}$ bubbles rising in anode channels $(6 \mathrm{ml} / \mathrm{min})$

\begin{tabular}{lll}
\hline Channel no. & $\begin{array}{l}\text { In normal gravity } \\
(\mathrm{mm} / \mathrm{s})\end{array}$ & $\begin{array}{l}\text { In microgravity } \\
(\mathrm{mm} / \mathrm{s})\end{array}$ \\
\hline 3 & 154 & 0.5 \\
4 & 149 & 0.5 \\
5 & 151 & 1.3 \\
6 & 143 & 1.8 \\
7 & 160 & 6.3 \\
8 & 142 & 2.5 \\
\hline
\end{tabular}

formed bubbly flow in normal gravity. Because of buoyancy force, the average velocity of bubbles rising in normal gravity was considerable high (Table 1) in comparison with the mean velocity of feeding liquid at the entry of channel of $1.82 \mathrm{~mm} / \mathrm{s}$ when the methanol solution flow rate was kept at $6 \mathrm{ml} / \mathrm{min}$. The visual observation showed that when the microgravity environment was built, the bubbles moving was slowed down at once. Bubbles average velocities in different channels in microgravity are listed in Table 1.

At the same moment in microgravity, bubble size in Fig. 5b was smaller than that in Fig. 5a. It is because the disturbing of mainstream of $15 \mathrm{ml} / \mathrm{min}$ was smarter than that of $6 \mathrm{ml} / \mathrm{min}$. When the inlet flow rate was $15 \mathrm{ml} / \mathrm{min}$, the mean speed of bubbles rising was also evidently higher than that at flow rate of $6 \mathrm{ml} / \mathrm{min}$ in microgravity (Tables 1 and 2). Considering that there was almost no visible influence of reactant inlet flow rate on the bubble rising speed in $1 \mathrm{~g}_{0}$ condition (Tables 1 and 2), we can conclude that in normal gravity, bubbles moving-up in anode channels is governed by buoyancy force rather than viscous drag of fluid flow. Tables 1 and 2 also show that the difference of the gas bubbles rising speed between the different liquid feeding flow rates in microgravity is extremely less than the mean speed difference between the different gravity levels. Larger bubbles (Fig. 5) and slower gas rising speed (Tables 1 and 2) in microgravity cause the worse performance of fuel cells (Fig. 4).

Table 2 Mean speed of $\mathrm{CO}_{2}$ bubbles rising in anode channels (15 $\mathrm{ml} / \mathrm{min})$

\begin{tabular}{llc}
\hline Channel no. & $\begin{array}{l}\text { In normal gravity } \\
(\mathrm{mm} / \mathrm{s})\end{array}$ & $\begin{array}{l}\text { In microgravity } \\
(\mathrm{mm} / \mathrm{s})\end{array}$ \\
\hline 3 & 148 & 5.0 \\
4 & 138 & 6.1 \\
5 & 144 & 15.6 \\
6 & 140 & 2.6 \\
7 & 136 & 9.2 \\
8 & 129 & 5.8 \\
\hline
\end{tabular}

\section{Conclusions}

Experimental study of a liquid fed direct methanol fuel cell has been conducted in different gravity conditions.

1. The gravitational effect on power performance of DMFC is considerable when the concentration polarization is dominant in fuel cells operation. The higher the current density is, the bigger the effect of gravity is.

2. Increasing methanol feeding molarity is conducive to weaken the effect of gravity on performance of liquid fed direct methanol fuel cells.

3. Increasing feeding flow rate of methanol solution from 6 to $15 \mathrm{ml} / \mathrm{min}$ could reduce the size of carbon dioxide bubbles. But the influence of gravity still exist.

Acknowledgements The authors appreciate the financial support from the National Natural Science Foundation of China (grant nos. 50406010, 50976006) and kindly help from Senior Engineer Ming Gang WEI at Drop Tower Beijing.

\section{References}

Argyropoulos, P., Scott, K., et al.: Gas evolution and power performance in direct methanol fuel cells. J. Appl. Electrochem. 29(6), 661-669 (1999a)

Argyropoulos, P., Scott, K., et al.: Carbon dioxide evolution in direct methanol fuel cells. Electrochim. Acta 44(20), 35753584 (1999b)

Guo, H., Ma, C.F., et al.: Heat and mass transfer and two phase flow in hydrogen proton exchange membrane fuel cells and direct methanol fuel cells. In: Proceedings of First International Conference on Fuel Cell Science, Engineering and Technology, pp. 471-476, 21-23 April 2003, Rochester, NY, USA (2003)

Guo, H., Jia, J.L., Kong, J., et al.: Two-phase flow in anode interdigital flow bed of a liquid fed direct methanol fuel cell. In: Proceedings of 13th International Heat Transfer Conference, 13-18 August 2006. Sydney, Australia, Begell House, paper number: ENR-04 (2006)

Guo, H., Zhao, J.F., Lv, C.P., et al.: Experimental study of fuel cells performance in short term microgravity condition. J. Eng. Thermophys. 29(5), 865-867 (2008a, in Chinese)

Guo, H., Zhao, J.F., Ye, F., et al.: Two-phase flow in fuel cells in short-term microgravity condition. Microgravity Sci. Technol. 20(3-4), 265-269 (2008b)

Guo, H., Zhao, J.F., Liu, X., et al.: Experimental study of performance of proton exchange membrane fuel cells in short-term microgravity condition. J. Eng. Thermophys. 30(8), 13761378 (2009a, in Chinese)

Guo, H., Wu, F., Ye, F., et al.: Two-phase flow in anode flow field of a small direct methanol fuel cell in different gravity. Sci. China, Ser E-Technol. Sci. 52(6), 1576-1582 (2009b) 
Lu, G.Q., Wang, C.Y.: Electrochemical and flow characterization of a direct methanol fuel cell. J. Power Sources 134(1), 33-40 (2004)

Nordlund, J., Picard, C., et al.: The design and usage of a visual direct methanol fuel cell. J. Appl. Electrochem. 34(8), 763770 (2004)

Scott, K., Taama, W.M., et al.: Engineering aspects of the direct methanol fuel cell system. J. Power Sources 79(1), 43-59 (1999)

Scott, K., Argyropoulos, P., et al.: Electrochemical and gas evolution characteristics of direct methanol fuel cells with stainless steel mesh flow beds. J. Appl. Electrochem. 31(8), 823-832 (2001)
Yang, H., Zhao, T.S., et al.: In situ visualization study of $\mathrm{CO}_{2}$ gas bubble behavior in DMFC anode flow fields. J. Power Sources 139(1-2), 79-90 (2005a)

Yang, H., Zhao, T.S., et al.: Pressure drop behavior in the anode flow field of liquid feed direct methanol fuel cells. J. Power Sources 142(1-2), 117-124 (2005b)

Yang, W.M., Chou, S.K., Shu, C.: Effect of current-collector structure on performance of passive micro direct methanol fuel cell. J. Power Sources 164(2), 549-554 (2007)

Zhang, J., Yin, G.P., Lai, Q.Z., et al.: The influence of anode gas diffusion layer on the performance of low-temperature DMFC. J. Power Sources 168(2), 453-458 (2007) 